\title{
RELAÇÕES DE GÊNERO, INFÂNCIA E ASSISTÊNCIA SOCIAL: REGISTROS SOBRE MENINAS ACOLHIDAS NO Asilo de ÓRFÃs SÃo VicEnTE dE PAULO (FLORIANÓPOLIS, SANTA CATARINA, 1904-1930)
}

Gender relations, childhood and social assistance: records about girls taken to the São Vicente de Paulo Orphans' Asylum (Florianópolis, Santa Catarina, 1904-1930)

Relaciones de género, infancia y asistencia social: registros sobre niñas llevadas al Asilo de Huérfanos de São Vicente de Paulo (Florianópolis, Santa Catarina, 1904-1930)

\author{
SILVIA MARIA FÁVERO AREND ${ }^{\text {** }}$ \\ CHIRLEY BEATRIZ DA SILVA VIEIRA ${ }^{\text {I***}}$
}

DOI: http://dx.doi.org/10.1590/S2178-14942020000200005

\footnotetext{
' Universidade do Estado de Santa Catarina (UDESC) - Florianópolis (SC), Brasil.

*Professora do Programa de Pós-Graduação em História da Universidade do Estado de Santa Catarina - UDESC (smfarend@gmail.com).

(D) https://orcid.org/0000-0002-3262-5596

**Doutoranda do Programa de Pós-Graduação em Educação da Universidade do Estado de Santa Catarina - UDESC (schirleypsi@gmail.com).

(D) https://orcid.org/0000-0002-7400-8721
}

Artigo recebido em 01 de janeiro de 2020 e aprovado para publicação em 20 de março de 2020. 


\title{
Resumo
}

Este artigo visa demonstrar que as ações de caráter filantrópico em favor das populações infantojuvenis brasileiras pobres foram norteadas por discursos relativos a relações de gênero e de classe social. Inicialmente, com base em análise quantitativa e qualitativa, apresentamos o perfil das meninas pobres acolhidas entre 1904 e 1930 no Asilo de Órfãs São Vicente de Paulo, principal instituição de abrigo do estado de Santa Catarina (Brasil) para meninas. Posteriormente, descrevemos quais foram as atividades desempenhadas pelas meninas após a saída da instituição. Entre as atividades desempenhadas por elas destacam-se os serviços domésticos, o exercício do magistério e a carreira religiosa.

PALAVRAS-CHAVE: Infância; Relações de gênero; Assistência social; Educação.

\begin{abstract}
This article aims to demonstrate that philanthropic actions in favor of poor Brazilian children and youth populations were guided by discourses related to gender and social class relations. Initially, from a quantitative and qualitative analysis, we present a profile of poor girls welcomed between 1904 and 1930 at the São Vicente de Paulo Orphans' Asylum, the main shelter institution in the state of Santa Catarina (Brazil) for girls. Later, we will describe the activities performed by the girls after leaving the institution. Among the activities performed by them, domestic services, teaching, and religious career stand out.
\end{abstract}

KEYWORDS: Childhood; Gender relations; Social assistance; Education.

\section{RESUMEN}

Este artículo tiene como objetivo demostrar que las acciones filantrópicas en favor de los niños y jóvenes pobres de Brasil se guiaron por discursos relacionados con el género y las relaciones de clase social. Inicialmente, a partir de un análisis cuantitativo y cualitativo, presentamos un perfil de niñas pobres acogidas entre 1904 y 1930 en el Asilo de Huérfanos de São Vicente de Paulo, la principal institución de acogida en el estado de Santa Catarina (Brasil) para niñas. Más adelante, describiremos las actividades realizadas por las niñas después de salir de la institución. Entre las actividades que realizan, destacan los servicios domésticos, la docencia y la carrera religiosa.

PALABRAS CLAVE: Infancia; Relaciones de género; Asistencia social; Educación. 


\section{CONSIDERAÇÕES INICIAIS}

as três primeiras décadas do século $X X$, a sociedade brasileira delineou cenários
nos campos político, econômico e social que se distinguiam de sua trajetória até então. No campo político, com a instauração do regime republicano em 1889, a expectativa era incorporar maior número de grupos sociais no novo sistema eleitoral. Tal fato acabou não se concretizando na república liberal, que era gerida sobretudo por cafeicultores paulistas e mineiros e por oficiais de alta patente do Exército. No âmbito da economia, por sua vez, observaram-se a consolidação do país como um dos principais produtores de café do mundo e a emergência de um parque industrial, ainda bastante acanhado, principalmente no Distrito Federal e nas cidades de São Paulo, Recife, Belo Horizonte e Porto Alegre.

No campo social, as elites republicanas, orientadas pelo ideário burguês, buscaram introduzir outras práticas e valores no âmbito da família e da infância. Esse processo pôde ser observado em nível nacional com a promulgação do Código Civil de 1916 (Brasil, 1916) e do Código de Menores de 1927 (Brasil, 1927), assim como por meio de ações higienistas no campo da saúde e de caráter filantrópico no âmbito da assistência social. Para as historiadoras Gisele Sanglard e Maria Antónia Lopes (2018: 282):

No Brasil, a emergência da questão social está vinculada ao fim do escravismo. Para resolvê-la, médicos, juristas e filantropos se uniram para a criação de instituições que objetivassem 0 combate à mortalidade infantil, que tornassem os menores abandonados aptos para o trabalho e que combatessem as doenças. Em comum, a ideia do trabalho como regenerador e a fé na ciência. (grifo do autor)

As autoras afirmam que a historiografia brasileira, por um longo tempo, investigou de forma dissociada os temas da pobreza e da assistência social. Neste artigo, por meio de estudo de caso, buscamos demonstrar que as ações de caráter filantrópico em favor das populações infantojuvenis brasileiras pobres foram pautadas em discursos relativos a relações de gênero e classe social. Ou seja, as ações concernentes a processos de acolhimento/desligamento de abrigos e os procedimentos relativos à permanência das pessoas nos asilos e à educação geral e escolar, entre outras práticas levadas a cabo pelas instituições filantrópicas, vislumbravam no horizonte das meninas os restritos espaços sociais reservados às mulheres pobres da sociedade brasileira nas primeiras décadas do século XX. Somente com o advento de políticas sociais motivadas pela mobilização de discursos feministas nos anos de 1970, esse cenário de exclusão social começou a alterar-se no país, ainda que muito lentamente. 
0 referido processo de modernização da sociedade brasileira ocorreu de forma distinta e a partir de temporalidades diversas nos diferentes estados da Federação. Na capital administrativa e política do estado de Santa Catarina, localizada na Ilha de Santa Catarina, esse cenário comporta permanências e rupturas. No plano econômico, o excedente da produção pesqueira, atividade econômica desenvolvida na região desde o século XVIII, continuou sendo enviado a outras regiões do Brasil. Nas pequenas indústrias, sobretudo de bens de consumo, labutava parte importante da mão de obra da cidade. Por sua vez, a burocracia municipal, estadual, federal e eclesiástica, o Exército, a Marinha e as profissões liberais empregavam parcela significativa da população do sexo masculino da cidade (Neckel, 2003). No âmbito político, além de o município ter seu nome alterado de Nossa Senhora do Desterro para Florianópolis, observou-se a emergência de um grupo dirigente vinculado ao Partido Republicano Catarinense (PRC), cuja orientação programática era o liberalismo. No plano urbanístico, a cidade passou por um conjunto de remodelações com o objetivo principal de projetar o espaço urbano sob uma lógica capitalista e higienista, além de afastar as populações pobres da zona central da cidade (Cherem, 2001: 297-397).

Em relação à assistência social, com o início das atividades das Irmãs da Divina Providência, no fim do século XIX, quando passaram a administrar instituições católicas nas áreas de saúde, educação e assistência social, verificaram-se alterações nas relações sociais presentes nesse campo, com base nos princípios da filantropia. Segundo a historiadora Irma Rizzini (1990), a filantropia procurou romper com os métodos da assistência caritativa, que eram considerados ultrapassados. A autora afirma que a proposta filantrópica era vista como inovadora, mesmo dando continuidade à obra da caridade. De acordo com Rizzini (1990: 80), a filantropia objetivava "Não mais a esmola que humilha, mas a reintegração social daqueles que seriam os eternos clientes da caridade: os desajustados".

Entre as instituições católicas de assistência social da cidade voltadas para a infância pobre, incluindo órfãos e órfãs, destacava-se o Asilo de Órfãs São Vicente de Paulo', criado pela Irmandade do Divino Espírito Santo em 1904. O Asilo São Vicente de Paulo desenvolveu atividades por várias décadas, sendo considerado, até 1960, o principal abrigo para crianças e jovens do sexo feminino do estado de Santa Catarina. Este artigo tem por objetivo identificar o perfil das pessoas que estiveram abrigadas na instituição entre 1904 e 1930, bem como 0 destino das meninas e jovens depois de sua saída do asilo nesse período².

0 recorte temporal da investigação, compreendido entre 1904 e 1930, justifica-se por dois eventos de natureza diferente. Em 1904, o asilo passou a ter como público-alvo somente crianças do sexo feminino. Em 1927, o presidente da República Washington Luiz promulgou um código de menores que regulamentaria, no campo social, as ações desenvolvidas em favor 
da infância considerada, do ponto de vista jurídico, "abandonada, delinquente e trabalhadora". Tal lei, vigente em todo o território nacional, buscou alterar determinados procedimentos, relativos ao abrigamento de crianças, adolescentes e jovens, praticados desde longa data no país. Este artigo não adentrará na análise desse outro tempo da assistência social no Brasil, que era regido pelos ditames dos juízes de menores ${ }^{3}$.

Para a construção do presente artigo, foram utilizadas informações localizadas em fontes documentais produzidas pela Irmandade do Divino Espírito Santo, mantenedora do asilo. 0 Livro de Atas da instituição datado de 1904 registra o que se discutia nas reuniões ordinárias e extraordinárias dos "irmãos" e das "irmãs" (IDES, 1904 a 1909). 0 Livro de Inscrição 1911-1937 das asiladas contém os prontuários emitidos para cada pessoa que ingressou na instituição. Nesse prontuário, preenchido preferencialmente pelo mordomo das órfãs, eram registradas as seguintes informações: nome e sobrenome da criança, adolescente ou jovem, idade, filiação, cor, data de ingresso na instituição, responsável pela entrega ao asilo, histórico no interior do asilo — processo de escolarização, hospitalização, falecimento, fuga, casamento, entre outras ações - e desligamento da instituição (IDES, 1937). Utilizam-se também as informações contidas no Regimento Interno do Asilo de Órfãs São Vicente de Paulo, de 20 de dezembro de 1923 (IDES, 1923), e nos relatórios anuais da instituição apresentados à Mesa Administrativa entre 1920 e 1930. Esse acervo documental está sob a guarda do Memorial da Irmandade do Divino Espírito Santo (IDES), localizado no interior da instituição 4 . Em termos metodológicos, as fontes documentais serão analisadas com base em perspectiva quantitativa e qualitativa.

Os documentos produzidos por instituições de abrigamento no Brasil no período em estudo, tais como os anteriormente citados, caracterizam-se por serem construídos segundo perspectiva adultocêntrica, pois apresentam visão centrada na ótica dos gestores quanto ao que se sucedia nos orfanatos, elidindo as possíveis tensões, disputas internas e, geralmente, por não registrarem as vozes infantojuvenis (Sosenski, 2016). Essa constatação relativa às fontes documentais é importante, pois impõe determinados limites na produção da narrativa histórica, especialmente quando se almeja produzir uma história da infância e juventude sob a ótica das relações de gênero (Strimelle, 2003).

Foram localizadas quatro investigações de caráter historiográfico, produzidas a partir dos anos 2000, que abordam a temática do abrigamento de crianças e jovens do sexo feminino em instituições católicas brasileiras no período em tela (Negrão, 2004; Caldeira, 2014; Duarte, 2013; Scremin, 2009). De maneira geral, os quatro estudos demonstraram que as instituições de assistência, criadas e posteriormente conduzidas segundo a ótica da filantropia, procuraram garantir a sobrevivência das meninas consideradas órfãs, mas sem Ihes alterar 
substancialmente a condição de classe social. Há dois estudos que tratam do Asilo de Órfãs São Vicente de Paulo. A historiadora Luisa Tombini Wittmann (2005) analisou como ocorreu 0 processo de acolhimento nessa instituição, nos anos de 1904 e 1905, de dez crianças indígenas sequestradas pelos colonizadores. Sobre o acolhimento e a escolarização de pessoas do sexo feminino na instituição nas primeiras décadas do século XX dispõe-se somente do estudo da psicóloga Chirley Beatriz da Silva Vieira (2018).

Os estudos historiográficos mencionados e a referida documentação apontam para a necessidade de uma análise teórica de caráter interseccional no que tange às ações instituídas no Asilo de Órfãs São Vicente de Paulo para as meninas e as jovens abrigadas. A análise interseccional é tributária dos debates feministas, caracterizando-se pela proposição epistemológica da pesquisadora estadunidense Kimberlé Crenshaw (2002). A jurista afirma, em texto considerado clássico:

Utilizando uma metáfora de interseção, faremos inicialmente uma analogia em que os vários eixos de poder, isto é, raça, etnia, gênero e classe constituem as avenidas que estruturam os terrenos sociais, econômicos e políticos. É através delas que as dinâmicas do desempoderamento se movem. Essas vias são por vezes definidas como eixos de poder distintos e mutuamente excludentes; o racismo, por exemplo, é distinto do patriarcalismo, que, por sua vez, é diferente da opressão de classe. Na verdade, tais sistemas, frequentemente, se sobrepõem e se cruzam, criando interseções complexas nas quais dois, três ou quatro eixos se entrecruzam (Crenshaw, 2002: 177).

0 paradigma epistemológico da interseccionalidade vem sendo utilizado em estudos feministas e sobre relações de gênero de diferentes nacionalidades (sobretudo pós-coloniais). Essa perspectiva preconiza a não hierarquização dos marcadores sociais no estudo dos processos relativos à (re)produção das desigualdades sociais. Postula, também, que as experiências referentes às relações de gênero, classe social, etnia/raça, geração ou outras sejam analisadas no seu entrecruzamento (Hirata, 2014). Defende-se aqui que a utilização do paradigma da interseccionalidade poderá trazer resultados mais profícuos para as análises das políticas socais implementadas para as infâncias brasileiras no século XX.

\section{PERFIL DAS MENINAS ACOLHIDAS NO ASILO DE ÓRFÃS SÃO ViCENTE DE PAULO ENTRE 1904 E 1930}

A Irmandade do Divino Espírito Santo foi fundada na Vila de Nossa Senhora do Desterro no ano de 1773, aproximadamente duas décadas depois da chegada dos migrantes açorianos e madeirenses aos territórios localizados no sul da américa portuguesa. Essa ordem, de caráter leigo, tinha por finalidade primeira a difusão do culto ao Espírito Santo entre ho- 
mens, mulheres, jovens e crianças da região. No decorrer do tempo, a irmandade passou a contar com número expressivo de pessoas que professavam a fé católica. Entre os "irmãos" e "irmãs", havia importantes personagens do cenário político-administrativo da província, que viria a ser o estado de Santa Catarina.

Foi somente no início do século XX que a instituição passou a desenvolver ações no campo da assistência social para a infância em Florianópolis. Por determinação de d. José de Camargo Barros, bispo da diocese de Curitiba, localizada no estado do Paraná, as ordens religiosas deveriam pagar $10 \%$ da renda da entidade ao bispado ou realizar ações no campo da caridade, tais como a criação de orfanatos e asilos para idosos, ações pastorais, etc. Essa medida do bispado de Curitiba era tributária do processo de romanização pelo qual passava a Igreja Católica na época. A romanização visava, entre outros objetivos, à maior ingerência dos católicos sobre a população pobre urbana, que, no Brasil, começava a ter contato, nesse período, com ideários do socialismo e do anarquismo em função da emergência da industrialização (Arend; Silveira, 2018).

As paróquias sediadas no estado de Santa Catarina até o ano de 1908 respondiam à diocese de Curitiba. Os membros da Irmandade do Divino Espírito Santo, objetivando cumprir os ditames do bispado de Curitiba, optaram por criar um orfanato na cidade de Florianópolis. No ano de 1900, por meio de convênio firmado com a igreja matriz da cidade, atual Catedral Metropolitana, a entidade, inicialmente denominada de Orphanato Santa Catharina, passou a acolher crianças órfãs de ambos os sexos.

No século XIX, o destino de parcela de bebês e crianças pobres órfãs e/ou abandonadas da região era o acolhimento no Hospital de Caridade, primeiramente por meio do instituto sociojurídico da Roda dos Expostos e, então, pelo envio das crianças às casas das amas de leite, pagas pela Câmara Municipal de Nossa Senhora de Desterro. 0 hospital era administrado pela Irmandade do Senhor Jesus dos Passos, ordem católica leiga. Havia, ainda, parcela da população infantojuvenil pobre, órfã e/ou abandonada do município que era enviada por parentes às residências de famílias mais abastadas ou de pessoas trabalhadoras. Essas relações sociais, presentes há longa data na sociedade brasileira, foram denominadas pela antropóloga Cláudia Fonseca (1995) de "circulação de crianças". Ressalta-se esse cenário "híbrido" relativo ao acolhimento de crianças e jovens órfãs e/ou pobres da região, pois a historiografia brasileira não mencionou por muito tempo os que trabalhavam diariamente para "pagar" pela sua subsistência.

No fim do século XIX, um grupo de irmãs da Divina Providência, congregação católica originária da Alemanha, transferiu-se para Florianópolis para atuar em três setores: na administração do Hospital de Caridade, na criação de um convento e na gerência de uma 
instituição de ensino escolar para meninas e jovens das famílias abastadas do estado de Santa Catarina. Em 1898, as freiras criaram o Colégio Coração de Jesus e um convento. A Irmandade do Divino Espírito Santo firmou convênio com as Irmãs da Divina Providência, as quais passaram a gerir o recém-instituído Orphanato Santa Catharina.

Entre 1900 e 1910, o asilo teve como sede o convento das irmãs. Durante esse período, importantes resoluções foram tomadas pelos membros da Irmandade do Divino Espírito Santo, as quais por décadas nortearam as ações implementadas na instituição de abrigamento. Em 1904, foi decidido que o asilo passaria a ter como público-alvo somente crianças e jovens do sexo feminino. A instituição buscaria assegurar às asiladas o ensino escolar elementar e religioso, bem como outros saberes necessários ao desempenho de atividades laborais no futuro de suas vidas. A administração do asilo seria realizada de forma conjunta pelos membros da Irmandade do Divino Espírito Santo, pelos religiosos da Conferência de São José da Sociedade São Vicente de Paulo e pelas freiras. As Irmãs da Divina Providência manteriam a gerência da instituição no tocante aos recursos humanos. Por fim, em 1904, o orfanato teve seu nome alterado para Asylo de Órphãs São Vicente de Paulo, em homenagem ao religioso francês Vincent de Paul, o qual dedicou parte de sua vida à caridade e foi canonizado pela Igreja Católica.

Em 1910, foi inaugurado o prédio do asilo, construído em um terreno situado próximo ao centro da cidade de Florianópolis, o qual foi doado pela devota católica Maria Francisca de Paula Braga. A edificação continha os quartos das asiladas e das freiras, no segundo andar, e, no primeiro andar, a cozinha, o refeitório, o templo e os ambientes para a realização de atividades laborais e relativas ao ensino. Em 1920, o prédio foi ampliando por meio de recursos financeiros oriundos do governo do estado de Santa Catarina, sendo obedecidas as normas de higiene prescritas na época. 0 relatório de 1920 do provedor da Irmandade do Divino Espírito Santo afirmou sobre a edificação:

Graças, sobretudo a excelsa bondade do eminente Governador do Estado, Dr. Hercílio Pedro da Luz, amparando junto do Congresso Representativo a justa pretensão, há longos annos, por nós mantida, de ampliar o edifício do Asylo, podemos no anno findo de 1920, com o auxílio votado em apólices, e paga ao contratante Theodoro Gründel, por saldo de contas, a importância de 7:500\$000, inauguramos a $2^{\text {a }}$ Ala do estabelecimento, que fica assim, dotado, de amplos salões, para 4 dormitórios, salas de refeições, de trabalhos, etc., tudo mantido de excelentes condições hygienicas, com muito ar, muita luz, com capacidade para perto de 100 creanças. A área do nosso edifício ficou elevada a $324 \mathrm{~m}^{2}$. 0 nosso edifício, nas condições actuais, com as suas 28 janelas de frente e situado na belíssima praça 17 de Novembro e em baixo, considerado o mais salubre desta cidade, já se impõe a consideração pública, que, incontestavelmente, vota-lhe as mais justas sympathias (IDES, 1920). 
A ata da primeira reunião extraordinária realizada pelos membros da Irmandade do Divino Espírito Santo em 1904 apresentava, logo em sua abertura, o regulamento interno para o funcionamento do Asilo de Órfãs São Vicente de Paulo. 0 documento informava que a entrega de uma criança à instituição ocorreria tendo em vista os seguintes requisitos: "a) ser a menina órfã de pai e mãe; b) ter cinco anos de idade no mínimo e dez no máximo; c) no caso extraordinário de ser a menina órfã somente de pai ou mãe e não possuir esta, ou aquele, a moralidade precisa, ou ser reconhecidamente indigente" (IDES, 1904 a 1909: 3-5).

Um segundo regimento foi aprovado no fim de 1923, regulamentando em 37 capítulos como deveria funcionar o asilo ${ }^{5}$. Ao entrar em vigor em $1^{\circ}$ de janeiro de 1924 , o regimento apresentava novas regras quanto à admissão das meninas:

CAPÍTULO III - Da admissão - Art. 4. - Serão somente admitidas meninas pobres e desvalidas, de 3 até 10 annos. Art. 5. - Nenhuma orphã será recebida sem ordem escripta do Provedor. Art. 6. - Esta ordem será dada em requerimento que tem de ser apresentado pelo interessado. $\S$ Único - Antes de ser dada a ordem, o Provedor mandará ouvir o Mordomo das Orphãs sobre o assumpto do requerimento. Art. 7. - A petição alludida trará o nome, estado e residência do requerente; nome, filiação, naturalidade da creança e será instruída com os seguintes documentos: $1^{\circ}$.) Certidão de idade ou documento que a supra, provando não ter a menina menos de três annos e mais de dez. Na ausência de taes meios de prova, a juízo do Provedor, poderá acceitar, nesse sentido, declaração firmada por duas pessoas de reconhecida idoneidade; $2^{\circ}$.) Attestado de autoridade civil ou eclesiástica declarando o estado de indigência; $3^{\circ}$.) Attestado médico declarando que a creança não soffre de moléstia incurável ou contagiosa. § Único Em casos excepcionaes, o pedido de entrada da menor orphã e desvalida pode ser feito por autoridade judicial ou policial, instruindo, sempre que possível, com os documentos constantes deste artigo (IDES, 1923: 2-4).

Verifica-se, no hiato de 20 anos, que em grande parte os requisitos exigidos para o ingresso de uma pessoa no asilo foram alterados. A primeira alteração dizia respeito à idade necessária para o ingresso na instituição. A partir de 1924, seriam admitidas crianças de no mínimo 3 anos de idade. Possivelmente, essa mudança estava associada ao elevado índice de mortalidade infantil das crianças acolhidas no Hospital de Caridade. Ainda havia bebês, de ambos os sexos, considerados abandonados, que eram enviados à casa de saúde. No hospital, as crianças tinham contato diário com patologias de diferentes ordens, que poderiam levá-las à morte. As meninas abandonadas que viviam no hospital eram transferidas para o asilo somente após completarem 5 anos. Transferi-las para o orfanato com idade inferior garantiria a sobrevivência a mais meninas. Em relação à saúde, observa-se ainda que a criança que portasse "moléstia incurável ou contagiosa" não poderia ser admitida no orfanato. A primeira restrição justificava-se pela ausência de recursos humanos e financeiros e a segunda 
em função da mortalidade infantil. A idade de 10 anos, por sua vez, não foi modificada no regimento de 1923, ou seja, considerava-se que até essa faixa etária ainda era possível educar as asiladas de acordo com práticas e valores burgueses e católicos.

Outra questão importante foi a imposição, em 1924, de comprovar-se a idade da menina por meio de documento de caráter oficial ou emitido por pessoas consideradas idôneas. De forma ainda lenta, o Estado brasileiro (ou quem o representava) buscava gerir a população tendo em vista as idades da vida. A gerência da população também dava-se nos dados que deveriam ser preenchidos na ficha de candidatura da menina. Além da filiação, era preciso informar o local de residência e a naturalidade. Esses dados eram relevantes em um estado da Federação, como era o caso de Santa Catarina, em que parcela significativa da população era descendente de estrangeiros ou era estrangeira.

A outra alteração de suma importância introduzida no regimento de 1923 estava associada à condição de pobreza da pessoa. A partir desse período, era preciso comprovar com atestado, emitido por autoridade civil ou eclesiástica, que a menina era "pobre e desvalida". A exigência desse requisito, muitas vezes não cumprido pelas pessoas, informava sobre um processo sociopolítico em curso na época que caracteriza o denominado assistencialismo. As elites florianopolitanas, laicas ou religiosas, buscavam por meio de exigências dessa natureza ter certa ascendência sobre os pobres urbanos (o que propiciava certo controle social), pois era necessário que mães, pais ou parentes estivessem inseridos em determinadas redes sociais - compadrio, laborais, religiosas etc. - para obter o documento. Em 1904, a condição sine qua non para o ingresso na instituição era a orfandade dos dois ascendentes ou de somente um. Em 1923, esse requisito passou para segundo plano, sendo prioridade a condição de pobreza da menina. Tal fato comprova que a instituição poderia acolher pessoas pobres que tivessem pais e/ou mães vivos. Por fim, era enunciado no texto de 1923 sobre o grupo social ao qual competia a palavra final quanto ao ingresso da menina na instituição. Segundo esse regimento, o gestor da Irmandade do Divino Espírito Santo (provedor) e o do asilo (mordomo das órfãs) é que tomavam essa decisão naquele período. Esse cenário se modificaria na década de 1930, com a implementação do disposto no Código de Menores de 1927.

A quantidade de vagas existentes no asilo era decidida pelos membros que compunham a direção da Irmandade do Divino Espírito Santo, cabendo ao provedor da instituição sancionar a cada ano o número de vagas. Até a inauguração da sede do asilo, em 1910, as pessoas eram entregues ao convento das Irmãs da Divina Providência, que residiam em espaço anexo. Entre 1904 e 1910, a instituição abrigava, em média, 30 meninas. A partir de 1910, na nova sede, as vagas aumentaram para 100, o que correspondia ao número de leitos disponíveis na edificação. 0 montante dos recursos financeiros que sustentava a instituição 
provinha de diferentes fontes: doações de particulares, aluguéis dos imóveis pertencentes à Irmandade do Divino Espírito Santo e subvenções públicas (oriundas de governos do município, do estado e/ou da Federação). A instabilidade financeira reportada nos relatórios da instituição fazia com que muitos leitos não fossem ocupados. Entre 1910 e 1920, o número de vagas permaneceu em 30 vagas anuais, aumentando ligeiramente na década posterior ${ }^{6}$. A quantidade de vagas ofertadas no asilo para as meninas consideradas desvalidas não supria a demanda da cidade de Florianópolis, cuja população, em 1920, era de 41.338 pessoas (IBGE, 1920: p. 388). Uma parcela das meninas e jovens órfãs e/ou pobres continuava sendo enviada a casas de famílias afluentes para trabalhar como empregadas domésticas.

De acordo com o Livro de Atas 1904 a 1909, entre esses anos, ou seja, quando o asilo estava sediado no Convento da Irmãs da Divina Providência, ingressaram na instituição 69 meninas. Nos documentos consultados, as informações sobre as asiladas são bem esparsas. Sabe-se que, no decorrer daqueles anos, ocorreram oito falecimentos, nove meninas retornaram para suas famílias consanguíneas e uma para a residência de um padrinho. Em 1910, 27 asiladas foram transferidas para a nova sede da instituição.

Os prontuários presentes no Livro de Inscrição 1911-1937 fornecem um conjunto de informações que permitem esboçar um perfil das meninas e jovens abrigadas entre 1910 e 1930. Antes de prosseguir a análise, faz-se necessário comentário sobre as fontes documentais e a ética na pesquisa no âmbito da História da Infância e Juventude. Em função de os prontuários terem como foco a população infantojuvenil do sexo feminino abrigada em uma instituição brasileira durante o período republicano, essas fontes foram produzidas sob o instituto jurídico do segredo de justiça. Vale observar, também, que algumas dessas mulheres ainda estão vivas e residem na região da Grande Florianópolis. Entende-se que sem a autorização dessas pessoas não é possível divulgar informações sobre suas infâncias. Essas duas questões explicam a restrição da análise do artigo ao aspecto quantitativo.

Os prontuários informam que 159 meninas foram abrigadas no Asilo de Órfãs São Vicente de Paulo entre 1910 e 1930. Chama a atenção o fato de que 52 meninas foram transferidas para a instituição por pessoas que não possuíam grau de parentesco consanguíneo ou de compadrio com elas. Essas crianças possivelmente haviam sido submetidas à guarda informal de particulares por seus parentes, mas os novos responsáveis não encontraram meios para criá-las. Tal cifra indica que no período em estudo a assistência social às meninas pobres em Florianópolis passou a ocorrer de forma complementar nesses dois espaços, ou seja, famílias de acolhimento e instituição. Consta dos documentos que 19 meninas foram entregues à instituição somente pelas mães e 11 somente pelo pai; uma menina teve ingresso a pedido do pai e da mãe; 18 garotas ingressaram no asilo por intermédio de tios, avós e padrinhos; 
10 meninas foram transferidas do Hospital de Caridade, enquanto uma menina proveio do Hospital de Azambuja7. Quatro meninas entraram no abrigo por meio de solicitação feita pelo chefe de Polícia, do mesmo modo que pelo juiz de direito entraram duas. Somente uma menina ingressou pela intervenção do provedor da Irmandade do Divino Espírito Santo. Por fim, não há indicação de origem do ingresso de 13 pessoas. Há que se lembrar, ainda, que 27 eram oriundas do Orphanato Santa Catarina.

Os registros sobre a filiação das meninas realizados pelo mordomo das órfãs eram bastante lacunares, o que explica o motivo do cenário apresentado a seguir ser incompleto em vários aspectos. Parcela significativa das meninas acolhidas no asilo era órfã de mãe e pai ou somente de uma das figuras parentais. Ingressaram na instituição 42 meninas órfãs de mãe e pai, 20 órfãs de mãe e quatro órfãs de pai. Tal fato demonstra que o asilo procurava cumprir com o objetivo prescritos nos regimentos, de acolher as órfãs da região consideradas pobres. Verifica-se, todavia, que 29 meninas que entraram na instituição possuíam mãe e pai vivos; 39 somente com as mães vivas e 15 com o pai vivo. Possivelmente, essas mulheres eram mães solo, ou seja, criavam suas filhas sem contar com o auxílio e/ou a presença do pai da criança. A relação social em que o genitor desaparecia era frequente na sociedade brasileira desde o período imperial. A historiografia refere-se a essas pessoas como "órfãos de pais vivos" (Marcílio, 1998; Venâncio, 1999; Arend, 2011). Não possuir pai ou alguém que desempenhasse esse papel social, além dos aspectos relativos ao status social considerado inferior (filha de mãe solteira em sociedade que difundia os valores burgueses relativos à família), poderia significar condição de pobreza mais acentuada. Ou seja, a orfandade de fato (em oposição à inscrita na ordem jurídica) também estava presente na instituição. Por fim, consta o registro de oito crianças cuja filiação era desconhecida e não há informações a respeito de duas.

Em relação à idade de ingresso no orfanato, identificam-se três grupos etários. Noventa e nove meninas entraram na instituição quando tinham entre 7 e 11 anos, 41 foram asiladas quando tinham entre 3 e 6 anos e 12 tinham entre 12 e 16 anos. A respeito de duas pessoas não há informações. Consta que, contrariando as regras da instituiç̧ão, outras duas meninas ingressaram ainda bebês. A maior parte delas ingressou no asilo em uma idade em que ainda não estava totalmente apta para o labor, mas já havia tornado, para os homens e/ ou mulheres adultos que as criavam, um peso em diferentes aspectos relativos à subsistência (alimentação, vestuário, educação escolar etc). 0 pequeno número de meninas com 12 anos ou mais está associado à possibilidade de as mulheres pobres na época se tornarem trabalhadoras nas lides domésticas ou em outras atividades. Já as crianças pequenas demandavam mais cuidados em relação à maternagem e à saúde. Diferentemente do mundo rural, 
as crianças pequenas eram muitas vezes consideradas estorvos pelas populações urbanas que labutavam em ofícios em que estas não poderiam estar presentes. A cifra de 41 meninas acolhidas no asilo também está relacionada a esse fato.

As meninas que ingressaram no Asilo de Órfãs São Vicente de Paulo entre 1910 e 1930 eram majoritariamente brasileiras, apenas uma asilada era de nacionalidade estrangeira (alemã). Os dados acerca da naturalidade das meninas são absolutamente lacunares e passaram a ser inseridos no prontuário de cada interna somente após a implementação do regimento em 1924. Tendo em vista essa particularidade de cunho administrativo, há informações sobre a naturalidade de 23 asiladas. Dois terços das meninas haviam nascido em Florianópolis e em localidades próximas, tais como Santo Amaro da Imperatriz, Biguaçu, Tijucas e Laguna. Uma menina era oriunda da cidade de Itajaí, duas da cidade de Lages e uma do estado de Minas Gerais. A ação social realizada pela Irmandade do Divino Espírito Santo atendia à demanda de parcela dos pobres do sexo feminino da região.

De acordo com as informações presentes nos prontuários, 120 das meninas abrigadas no asilo foram identificadas como brancas $^{8}$, como pardas, foram identificadas 22 meninas e, como pretas, 10, sobre as demais, não há informações. Vale destacar que as denominações étnico-raciais aqui utilizadas são as da época, mais especificamente as registradas pelo próprio mordomo das órfãs.

Chama a atenção o pequeno número de meninas afrodescendentes da região acoIhidas no abrigo. Esse cenário pode estar associado a dois processos. 0 primeiro refere-se à existência de redes sociais de auxílio entre a população afrodescendente (composta, por vezes, de famílias de caráter extenso) da região, o que fazia com que as meninas não necessitassem ingressar no circuito da assistência social. 0 segundo processo, ainda relativamente a muitas crianças afrodescendentes pobres, era o fato de que muitas delas tinham como padrinhos e/ou madrinhas homens e mulheres pertencentes à camada média ou à elite da região, sendo acolhidas nas residências com o status social de filhos/as de criação. As relações de compadrio, há longa data presentes nas sociedades portuguesa e brasileira, eram de fundamental importância no processo de reprodução da desigualdade social (Arend, 2011: 66-67). Todavia, entende-se que essa questão necessita ser mais bem investigada.

A Figura 1, de caráter ilustrativo, mostra as asiladas com as Irmãs da Divina Providência, na década de 1920. A imagem sugere que a maior parte das meninas era branca, embora o filme em preto e branco, a qualidade da foto, a iluminação do ambiente e o efeito da passagem do tempo sobre o suporte fotográfico devam ser considerados para evitar conclusões peremptórias sobre o tema. 


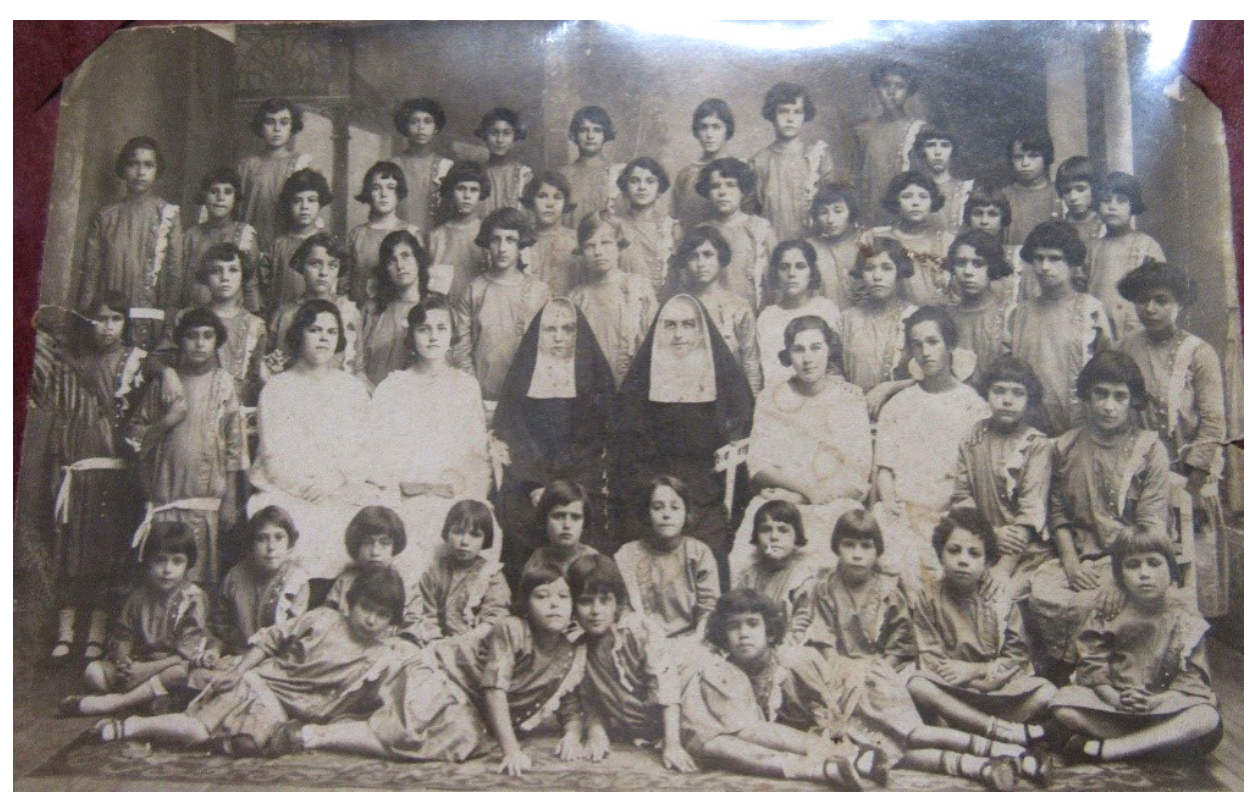

Figura 1 - Asiladas das Irmãs da Divina Providência na década de 1920 Fonte: Memorial da Irmandade do Divino Espírito Santo (IDES).

\section{DESTINOS DAS MENINAS ABRIGADAS NO ASILO SÃO VICENTE DE PAULO ENTRE 1904 E 1930}

O Asilo São Vicente de Paulo, entre 1910 e 1930, funcionava sob regime de internato. A rotina das meninas era orientada e fiscalizada pelas Irmãs da Divina Providência. Desde 0 momento em que acordavam pela manhã até a hora de dormir, as asiladas executavam muitas atividades. Juntamente com a educação escolar, as internas recebiam formação profissional, segundo informa o Regimento Interno do asilo de 1923:

Art. 2. - As aulas profissionaes do Asylo não se destinam a preparar operarias, mas donas de casa, conscientes dos seus deveres e responsabilidades, capazes de executar os mais necessários trabalhos domésticos e aptas para honesta e desembaraçadamente se manterem a custo do próprio trabalho, mediante o exercício de qualquer dos misteres aprendidos no Asylo. $\S 1^{\circ}$. - No curso profissional haverá aulas de costuras, bordados, confecções, pintura, flôres, chapéos, cosinha, confeitaria, lavanderia, engomação, floricultura, horticultura e puericultura, podendo ainda, além disso, a juizo da mesa Administrativa, ser introduzidos outros misteres. § $2^{\circ}$. - As asyladas que revelarem notável aptidão para os estudos, será facultado fazer o curso na Escola Nomal, dando-se-lhes, porém, as mais indispensáveis noções de serviço doméstico (IDES, 1923: 1-2). 
0 enunciado no Artigo 2 do regimento do asilo indica que a educação escolar (curso primário) e a profissional ministradas às internas visavam a dois objetivos associados a relações de gênero e classe social. A educação, por um lado, tinha em vista que as meninas no futuro fossem boas donas de casa, conforme o que prescrevia a norma familiar burguesa. Por outro, buscava garantir que essas pessoas, na vida adulta, pudessem manter-se financeiramente com um trabalho de caráter honesto. Esse labor poderia ser desempenhado por mulheres pobres em diferentes atividades: realizando serviços domésticos e relativos à maternagem (babá), em residências de famílias das camadas médias e das elites, trabalhando em oficinas ou por conta própria como costureiras, chapeleiras, bordadeiras etc., exercendo ofícios como lavadeiras e engomadeiras, auxiliares de limpeza em estabelecimentos comerciais e, ainda, como cozinheiras nas estalagens e bares existentes na cidade. Salienta-se que o caráter honesto aclara sobre a preocupação dos gestores da Irmandade do Divino Espírito Santo em garantir que as asiladas exercessem atividades que estivessem de acordo com a moral burguesa e católica vigente na época. 0 fantasma de atividades laborais consideradas imorais, tais como a prostituição, estava presente nesse contexto.

Em visitas realizadas ao asilo, homens e mulheres demonstravam o interesse em empregar meninas e jovens. Não consta dos documentos produzidos pela irmandade quais eram as formalidades dessas visitas, nem se posteriormente algum documento era firmado entre a instituição e a pessoa que empregava uma asilada. 0 que se encontra sobre esse tema não passa de uma informação no regimento interno do asilo, transcrito na primeira ata do ano de 1904, que foi assinada pelo provedor e pelos demais participantes da Mesa Administrativa da Irmandade do Divino Espírito Santo. O texto da ata apresentava o seguinte teor:

CAPÍTULO VIII - O chefe da família a quem for entregue uma órphã fica obrigado a zelar pela sua honestidade e boa conducta, mandando-a, sempre que for possível, ouvir missa aos domingos e cumprir com os demais preceitos da Religião Catholica e Apostólica Romana (IDES, 1904: 4).

Entre as 159 asiladas, 22 meninas, ao serem desligadas do asilo, foram trabalhar como empregadas domésticas ${ }^{9}$. Relatam-se dois casos cujo destino foram as lides domésticas. A asilada Margarida ingressou na instituição em um período anterior ao da construção do prédio, que foi realizada em 1911. Nesta data, ela tinha 13 anos e foi identificada pelo mordomo das órfãs como branca. Um ano depois, Margarida foi desligada do orfanato, indo residir, em setembro de 1911, na casa de família abastada que morava na cidade de Lages, localizada na região serrana do estado de Santa Catarina, a mais de 200 quilômetros de Florianópolis. A mãe de Margarida era moradora da capital do estado. Não se sabe se algum documento de 
caráter trabalhista ou de outra natureza foi firmado entre a responsável pela menor de idade e o seu patrão (IDES, 1937, p. 8).

Camélia ingressou no asilo quando completou 10 anos de idade, antes de 1910. Consta dos registros da instituição que os pais da menina eram desconhecidos, e ela foi identificada pelo mordomo como parda. A asilada foi desligada do abrigo em 1911, indo residir na casa de uma família de Florianópolis. Todavia, retornou para a instituição no mesmo ano. Possivelmente, em função de sua idade, Camélia não deu conta dos serviços domésticos imputados a ela. Por fim, há um último registro que informa que ela foi residir em outra casa de família de Florianópolis e lá permaneceu (IDES, 1937, p. 22).

De acordo com Ana Maria Melo Negrão (2004), o ideário da filantropia afirmava que gestores dos asilos femininos deviam enviar as meninas e jovens para trabalhar em casas de família das camadas médias ou das elites escolhidas pelas instituições religiosas. Essas transferências tinham por objetivo protegê-las de seus progenitores pobres, os quais representavam diferentes formas de ameaças. Assim, o melhor era entregá-las a outras famílias que poderiam garantir educação (não necessariamente a escolar) e sustento. Vale lembrar que esses préstimos eram pagos por meio do labor infantojuvenil.

As meninas do asilo frequentavam o curso primário de acordo com a legislação estadual relativa à educação escolar que vigorava no período. Os conteúdos escolares - leitura, caligrafia, linguagem, contas, geografia, história, educação cívica, canto e ginástica - eram ministrados pelas irmãs, bem como pelas internas que já haviam cursado o ensino primário e/ou o curso normal (SANTA CATARINA, 1913). Entre 1910 e 1930, a possibilidade de dar continuidade aos estudos foi ofertada somente para cinco meninas. Essas meninas consideradas aptas para o estudo frequentaram os bancos escolares do curso normal do Colégio Coração de Jesus. Após obterem o diploma de normalista, foram atuar em escolas localizadas sobretudo no interior do estado de Santa Catarina. As palavras do provedor da Irmandade do Divino Espírito Santo, presentes no relatório emitido em 1922, informam sobre o caso da asilada Dália, que se tornou normalista, conforme enunciado pela autoridade:

Asylada diplomada - A asylada que foi internada no Asylo na mais tenra idade, após um curso brilhante, concluiu o seu estudo na Escola Normal, o que constitui o motivo de grande jubilo para esta nossa casa. Logo que recebeu a sua carta de normalista, o Asylo prestou-Ihe significativa homenagem, promovendo-lhe um festival a que foi presente todas as asyladas, como os amigos desta instituição (IDES, 1922).

A obtenção do diploma de normalista e o exercício do magistério pode ter proporcionado nova condição social às asiladas. Além dos dois destinos, tornarem empregadas domésti- 
cas ou normalistas, outros dois constam registrados nas fontes. Três meninas casaram-se após o desligamento da instituição. No relatório da instituição de 1920 (IDES, 1920), o provedor da irmandade informa que a asilada Rosa casou-se com um lavrador e proprietário de terras que residia no distrito da Santíssima Trindade ${ }^{10}$. Para as despesas do casamento e do enxoval da jovem, foi gasto o montante de $100 \$ 000$ réis. Compareceram à cerimônia de casamento de Rosa, realizada na capela do asilo, importantes autoridades do estado de Santa Catarina da época, no entanto não se sabe como foram os outros dois casamentos. Outro destino das asiladas foi a carreira religiosa. Das 159 meninas que frequentaram o asilo no período em estudo, 14 ingressaram em uma ordem religiosa, com destaque para a Congregação das Irmãs da Divina Providência (IDES, 1937).

Por fim, 49 asiladas, após o desligamento da instituição, retornaram para a casa de mães, pais, irmãos ou outros parentes. A outra parcela, composta de 34 pessoas, foi desligada da instituição ao atingir a maioridade. Não é possível descrever qual tenha sido o destino dessas jovens em função de ausência de registros. Um número pequeno de meninas faleceu, e outras foram enviadas para o Hospital de Azambuja para tratamento psiquiátrico (IDES, 1937).

\section{CONSIDERAÇÕES FINAIS}

As ações realizadas no Asilo de Órfãs São Vicente de Paulo, entre 1904 e 1930, foram importantes para o acolhimento da população pobre de Florianópolis e região. Tais ações foram pioneiras no campo assistencial no estado de Santa Catarina no que tange aos princípios doutrinários da filantropia. As crianças e jovens acolhidas na instituição apresentavam as seguintes características: no período em que ingressava no asilo, tinha entre três e cinco anos, era majoritariamente branca, grande parte possuía um dos genitores vivos (geralmente a mãe), era de nacionalidade brasileira e a maioria era natural da região. Buscou-se realizar do ponto de vista teórico, análise interseccional considerando os marcadores de classe social, relações de gênero, etnia/raça e faixa etária.

Para as meninas acolhidas na instituição gerida por freiras católicas, buscava-se garantir a educação escolar primária e a católica, bem como a aquisição de saberes sobre ofícios que possibilitassem sua sobrevivência. Tendo em vista esse contexto, parcela das meninas, após a saída da instituição, continuou trabalhando nos serviços domésticos, outra, bastante pequena, passou a exercer o magistério e outra seguiu a carreira religiosa. Ou seja, a possibilidade de ascensão de classe social não estava no horizonte dessa política assistencial implementada para meninas da região. Foram necessárias várias décadas para que tal cenário fosse alterado. 


\section{NOTAS}

1 No texto do artigo, utilizou-se a grafia atual dos nomes das instituições de abrigo. Em relação às fontes documentais citadas, foi usada a grafia do período em estudo.

20 artigo apresenta os resultados parciais de uma investigação sobre as ações levadas a cabo no Asilo de Órfãs São Vicente de Paulo durante o século XX, realizada no Laboratório de Relações de Gênero e Família (LABGEF), da Universidade do Estado de Santa Catarina. Parte da pesquisa foi financiada com recursos financeiros oriundos do Conselho Nacional de Desenvolvimento Científico e Tecnológico (CNPq) e da Fundação de Amparo à Pesquisa e Inovação de Santa Catarina (FAPESC)/Edital do Programa de Apoio à Pesquisa da Universidade do Estado de Santa Catarina (PAP-UDESC) 2018-Termo de Outorga 2019TR615.

30 primeiro Juizado de Menores do estado de Santa Catarina foi criado em 1935 na cidade de Florianópolis.

40 acervo do Memorial da Irmandade do Divino Espírito Santo (IDES) foi organizado por meio do projeto de extensão intitulado "Mais de dois séculos de História: procedimentos técnicos para salvaguarda do acervo documental da Irmandade do Divino Espírito Santo", levado a cabo por docentes, técnicas universitárias e estudantes de doutorado e graduação da Universidade do Estado de Santa Catarina, com financiamento da Fundação Catarinense de Cultura (FCC). Disponivel em: <https://www.udesc.br/faed/idch/ides>. Acesso em: 18 dez. 2019.

50 Regimento Interno do Asilo de Órfãs São Vicente de Paulo, aprovado em 20 de dezembro de 1923, foi construído tendo por base as discussões sociojurídicas que deram origem ao Decreto Federal no 16.272, de 20 de dezembro de 1923, que regulamentava a assistência e a proteção a menores considerados abandonados e delinquentes.

6 Relatórios anuais apresentados pelo Provedor à Mesa Administrativa da Irmandade do Divino Espírito Santo, Memorial IDES.

70 Hospital de Azambuja foi criado em 1902 pelas Irmãs da Divina Providência, na cidade de Brusque, distante 200 quilômetros de Florianópolis. A instituição era constituída de uma casa de saúde, um orfanato e um hospital psiquiátrico.

8 No Livro de Atas, temos apenas o registro do nome das asiladas que ingressaram na instituição entre os anos 1904 e 1909. Possivelmente as informações presentes no Livro de Atas são provenientes de outro livro, no entanto esse documento não foi localizado no Memorial IDES.

9 Os nomes das meninas abrigadas no Asilo de Órfãs São Vicente de Paulo neste texto são fictícios. As asiladas tiveram nome e sobrenome registrados em seus prontuários a partir de 1910. 
10 Relatórios anuais apresentados pelo Provedor à Mesa Administrativa da Irmandade do Divino Espírito Santo, Memorial IDES.

\section{REFERÊNCIAS BIBLIOGRÁFICAS}

AREND, Silvia Maria Fávero. Histórias de abandono: infância e justiça no Brasil (década de 1930). Florianópolis: Mulheres, 2011.

AREND, Silvia Maria Fávero; Silveira, Chirley Beatriz Vieira da. A construção de um asilo para meninas desvalidas em Santa Catarina (1898-1910). História UNICAP, v. 5, n. 9, p. 47-59, 2018. Disponível em: <http://www.unicap.br/ojs/index.php/historia/article/view/1192>. Acesso em: 30 nov. 2019. https://doi. org/10.25247/hu.2018.v5n9.p47-59

BRASIL. Lei n. 3.071, de $1^{\circ}$ de janeiro de 1916. Código Civil dos Estados Unidos do Brasil. Diário Oficial da União: República dos Estados Unidos do Brasil, Rio de Janeiro, 05 jan. 1916.

BRASIL. Decreto número 17.943-A, de 12 de outubro de 1927. Consolida as leis de assistencia e protecção a menores. Collecção das Leis da República dos Estados Unidos do Brazil., Rio de Janeiro, 31 dez. 1927.

CALDEIRA, Jeane dos Santos. O Asilo de Órfãs São Benedito em Pelotas - RS (as primeiras décadas do século XX): trajetória educativa-institucional. Dissertação (Mestrado em Educação) - Universidade Federal de Pelotas, Pelotas, 2014.

CHEREM, Rosângela Miranda. Do sonho ao despertar: expectativas e paixões políticas no início republicano na capital de Santa Catarina. In: Brancher, Ana; Arend, Silvia Maria Fávero (orgs.). História de Santa Catarina no Século XIX. Florianópolis: Editora da UFSC, 2001. p. 297-347.

CRENSHAW, Kimberlé. Documentos para o encontro de especialistas em aspectos da discriminação racial relativos ao gênero. Estudos Feministas, Florianópolis, v. 10, n. 1, p. 171-188, 2002. Disponível em: <https:// periodicos.ufsc.br/index.php/ref/article/view/S0104-026X2002000100011/8774>. Acesso em. 12 dez. 2019.

DUARTE, Antônio Valdir Monteiro. Órfãs e desvalidas: a formação de meninas no Orphanato Municipal de Belém do Pará (1893-1931). Tese (Doutorado em Educação) - Universidade Federal de Uberlândia, Uberlândia, 2013.

FONSECA, Cláudia. Caminhos da adoção. São Paulo: Cortez, 1995.

HIRATA, Helena. Gênero, classe e raça: interseccionalidade e consubstancialidade das relações sociais. Tempo Social, v. 26, n. 1, p. 61-73, 2014. Disponível em: <http://www.scielo.br/scielo.php?pid=S010320702014000100005\&script=sci_abstract\&tlng=pt>. Acesso em: 20 dez. 2019. https://doi.org/10.1590/ S0103-20702014000100005

INSTITUTO BRASILEIRO DE GEOGRAFIA E ESTATÍSTICA (IBGE). Recenseamento Geral do Brazil de 1920. IBGE, 1920.

IRMANDADE DO DIVINO ESPÍRITO SANTO (IDES). Livro ata. Irmandade do Divino Espírito Santo, 1904 a 1909. Memorial IDES.

IRMANDADE DO DIVINO ESPÍRITO SANTO (IDES). Livro de inscrição 1911-1937. Irmandade do Divino Espírito Santo, 1937. Memorial IDES.

IRMANDADE DO DIVINO ESPÍRITO SANTO (IDES). Relatório apresentado à Mesa Administrativa de 1920. Irmandade do Divino Espírito Santo, 1920. Memorial IDES. 
IRMANDADE DO DIVINO ESPÍRITO SANTO (IDES). Relatório apresentado à Mesa Administrativa de 1922. Irmandade do Divino Espírito Santo, 1922. Memorial IDES.

IRMANDADE DO DIVINO ESPÍRITO SANTO (IDES). Regimento Interno do Asilo de Órfãs São Vicente de Paulo. Irmandade do Divino Espírito Santo, 1923. Memorial IDES.

MARCÍlIO, Maria Luiza. História social da criança abandonada. São Paulo: Hucitec, 1998.

NECKEL, Roselane. A república em Santa Catarina: modernidade e exclusão (1889-1920). Florianópolis: Editora da UFSC, 2003.

NEGRÃO, Ana Maria Melo. Infância, Educação e Direitos Sociais: "Asilo de Órfãs" (1870 - 1960). Campinas: UNICAMP/CMU, 2004.

RIZZINI, Irma. A assistência à infância na passagem para o século XX: da repressão à reeducação. Forum Educacional, Rio de Janeiro, v. 14, n. 2, p. 77-94, 1990. Disponível em: <http://bibliotecadigital.fgv.br/ojs/ index.php/fe/article/view/61112>. Acesso em: 18 dez. 2019.

SANGLARD, Gisele; LOPES, Maria Antónia. Pobreza e assistência: debates historiográficos. Tempo, v. 24, n. 2, p. 280-284, 2018. Disponível em: <http://www.scielo.br/scielo.php?script=sci_arttext\&pid=\$141377042018000200280\&/ng=pt\&nrm=iso >. Acesso em: 16 dez. 2019. https://doi.org/10.1590/tem-1980$542 \times 2018 v 240205$

SANTA CATARINA. Regulamento Geral da Instrução Pública. Santa Catarina, 1913.

SCREMIN, João Valério. Pobre coração de Maria: assistência e educação de meninas desvalidas em fins do século XIX e início do século XX. Dissertação (Mestrado em Educação) - Universidade Estadual de Campinas, Campinas, 2009.

SOSENSKI, Susana. Dar casa a las voces infantiles, reflexiones desde la historia. Revista Latinoamericana de Ciencias Sociales, Niñez y Juventud, v. 14, n. 1, p. 43-52, 2016. Disponível em: <http://revistaumanizales. cinde.org.co/rlcsnj/index.php/Revista-Latinoamericana/article/view/2328>. Acesso em: 22 dez. 2019.

STRIMELLE, Véronique. La gestion de la déviance des filles à Montréal au XIXe siècle. Les institutions du BonPasteur d'Angers (1869-1912). Revue d'Histoire de l'Enfance "Irrégulière", n. 5, p. 61-83, 2003. Disponível em: <http://journals.openedition.org/rhei/905>. Acesso em: 14 dez. 2019. https://doi.org/10.4000/rhei.905

VENÂNCIO, Renato Pinto. Famílias abandonadas: assistência à criança de camadas populares no Rio de Janeiro e em Salvador, séculos XVIII e XIX. Campinas: Papirus, 1999.

VIEIRA, Chirley Beatriz da Silva. Asilo de Órfãs São Vicente de Paulo e Escola São Vicente de Paulo: institucionalização e educação de meninas e moças (Florianópolis, 1900-1930). Dissertação (Mestrado em Educação) - Universidade do Estado de Santa Catarina, Florianópolis, 2018.

WITTMANN, Luisa Tombini. Atos do contato: histórias do povo indígena Xokleng no Vale do Itajai/SC (1850-1926). Dissertação (Mestrado em História) - Universidade Estadual de Campinas, Campinas, 2005. 